\title{
PROSES PEMBANGUNAN DAN FUNGSI RUANG RUMAH NIANG DI DESA WAE REBO
}

\author{
Karolus Torto Tandi \\ Program Studi Arsitektur, Fakultas Teknik, Universitas Dwijendra \\ karolus0394@gmail.com \\ Ir. I Ketut Adhimastra, M.Erg \\ Program Studi Arsitektur, Fakultas Teknik, Universitas Dwijendra \\ adhimastra@gmail.com
}

\begin{abstract}
Abstrak
Mbaru Niang merupakan rumah adat di Wae Rebo berbentuk rumah kerucut dengan jumlah tujuh buah dan memiliki eksotisme tersendiri, pembahasan diberbagai kalangan selalu menitik beratkan pada arsitektural Mbaru Niang sebagai fokus utama, sedangkan penelitian tentang ruang dalam pada bangunan bagaimana fungsi setiap tingkatan ruang, makna dibalik bentukan ruang dan sebagainya, belum banyak disentuh. Bagi masyarakat Wae Rebo, Mbaru Niang adalah bagian dari diri mereka sendiri, setiap tingkatan ruang pada Mbaru Niang mempunyai fungsi yang berbeda. Penelitian ini bertujuan untuk memperkaya data analisa, dan menambah wawasan bagi generasi penerus, bagaimana fungsi ruang pada setiap lantai dari Mbaru Niang. Metode semiotika dari Pierce digunakan dalam penelitian ini untuk mengidentifikasi setiap tanda dari makna-makna melalui jenis objeknya yaitu ikon, indeks, dan simbol. Hasil dari metode Piercian yang menggunakan ketiga objek diatas dapat memberikan kesimpulan bagaimana fungsi a ruang pada suatu Mbaru Niang terutama Mbaru Gendang.
\end{abstract}

Kata Kunci: Tradisi,Fungsi Ruang Mbaru Niang, Wae Rebo.

\begin{abstract}
Mbaru Niang is a traditional house in Wae Rebo in the form of a cone house with a total of seven pieces and has its own exoticism, discussions in various circles always focus on Mbaru Niang architecture as the main focus, while research on internal space in buildings is how each level of space functions, the meaning behind the formation space and so on, haven't been touched much. For the people of Wae Rebo, Mbaru Niang is part of themselves, each level of space in Mbaru Niang has a different function. This study aims to enrich the analysis data, and add insight for future generations, how the space functions on each floor of Mbaru Niang. Pierce's semiotic method is used in this study to identify each sign of meanings through the types of objects, namely icons, indexes, and symbols. The results of the Piercian method that uses the three objects above can provide conclusions on how the space functions in a Mbaru Niang, especially Mbaru Gendang.
\end{abstract}

Keywords: Tradition, Mbaru Niang Room Function, Wae Rebo.

\section{PENDAHULUAN}

Indonesia merupakan sebuah Negara multicultural yang kaya akan keanekaragaman budaya, suku, rasa dan agama. Masing-masing kebudayaan memiliki ciri khas dan keunikan sendiri, dan salah satu yang menjadi identitas utama dari kebudayaan tersebut adalah rumah adat. Rumah adat di Indonesia memiliki ciri khas dan arsitektural dan desain yang unik,karena rumah adat merupakan peninggalan masa lalu yang tumbuh dan berkembang berdasarkan adat istiadat daerah setempat yang memiliki nilai-nilai,filosofi dan makna tersendiri termasuk pula rumah adat yang berada di Desa Wae Rebo. 
Desa Wae Rebo adalah salah satu Desa tradisional yang berada di Kabupaten Manggarai,Pulau Flores,Provinsi Nusa Tenggara Timur yang masih melestarikan alam dan budaya asli mereka yang sudah dibangun oleh para nenek moyang mereka. Nenek moyang orang Wae Rebo bernama "Empo Maro". Empo Maro berasal dari Minangkabau,Sumatera Bentuk rumah adat Wae Rebo yang biasa disebut Mbaru Niang. "Mbaru" artinya adalah rumah dan "Niang" artinya adalah tinggi dan bulat. Sebenarnya masih ada lagi di Kampung Todo,hanya saja Mbaru Niang di kampong Todo hanya berdiri gagah tanpa ada lagi orang mendiami didalamnya.

Kehidupan masyarakat Wae Rebo sampai saat ini masih asli seperti yang diwariskan oleh leluhur mereka. Setiap individu yang berada dalam lingkaran kehidupan adat mereka merupakan bagian tak terpisahkan dari mekanisme sosial yang dijiwai oleh nilai adat dan istiadat masyarakat tersebut. Berbagai warisan kebudayaan yang beragam seperti upacara adat proses pembangunan rumah Niang,kepercayaan masyarakat sehari-hari dan rumah adat Niang ini merupakan perwujudan dari nilai kebudayaan yang masih dijaga dan menjadi landasan kuat pada masyarakat Wae Rebo. Usaha dan Upaya warga Wae Rebo dalam mempethanakan sejarah, budaya dan kearifan mereka ternyata tidak luput dari penglihatan salah satu organisasi dunia yaitu UNESCO. Organisasi tersebut menghadiahkan Desa Wae Rebo sebuah penghargaan UNESCO Asian Pacific Award for Cultural Heritage Conservation pada 27 Agustus 2012.Penghargaan tersebut adalah penghargaan tertinggi yang diberikan kepada mereka yang melakukan konservasi. terhadap suatu warisan budaya. Setiap rumah ada dua pintu, di depan, di belakang, serta empat jendela kecil. Masuk kedalam rumah yang remang-remang, terlihat langit-langit yang tinggi dan kayu konstruksi, Mbaru Niang terdiri dari lima tingkat yang masingmasing memiliki fungsi dan nama tersendiri.

Amos Rapoport dalam bukunya yang berjudul House Form and Culture (1969). Adalah suatu kesalahan jika kita menganggap bahwa masyarakat yang kita bicarakan secara esensial berbeda dengan masyarakat kita dalam hal tingkat pertemuan antara pemikiran simbolis dan fungsional.

Dalam upacara adat yang dilaksanakan oleh masyarakat Manggarai, leluhur (enpo) memiliki peranan yang sangat penting. Leluhur (empo) bagaikan jembatan dan jalan untuk sampai kepada Tuhan. Untuk mendatangkan rahmat dan berkat Allah, para anak cucu harus setia melaksanakan upacara adat (Janggur 2008 : 44-45).

Tujuh rumah Mbaru Niang yang dibuat oleh para nenek moyang mereka memiliki arti untuk menghormati 7 arah mata angin dari puncak-puncak gunung yang yang mengelilingi Kampung Waerebo. Hal itu mereka percayai sebagai cara untuk menghormati roh-roh yang memberikan mereka kesejahteraan. Semua Mbaru Niang berdiri di tanah datar dan dibangun mengelillingi sebuah altar yang disebut "Compang". Compang berdiri sebagai titik pusat dari ketujuh rumah tersebut dan dipercaya sebagai bangunan paling sakral yang ada di disana. Fungsi Compang adalah sebagai altar untuk memuji dan menyembah Tuhan serta para roh-roh nenek moyang.

Seluruh Mbaru Niang memiliki nama asli yang berbeda-beda, mereka adalah:

1. Niang Gendang

2. Niang Gena Mandok

3. Niang Gena Jekong (dibangun kembali pada tahun 2010)

4. Niang Gena Ndorom (dibangun kembali pada tahun 2009)

5. Niang Gena Keto

6. Niang Gena Jintam

7. Niang Gena Maro

\section{Identifikasi Masalah}


Berdasarkan latar belakang di atas maka permasalahan dalam penelitian ini adalah rumah adat merupakan asset nenek moyang yang perlu dilestarikan oleh generasi penerus bangsa, dalam hal ini rumah adat "Mbaru Niang" perlu dijaga dan dilestarikan sebagai salah satu identitas masyarakat Desa Wae Rebo.

\section{Rumusan Masalah}

a. Bagaimanakah pembagian dan fungsi ruang rumah Niang?

b. Bagaimanakan proses pembangunan rumah adat Wae Rebo "mabaru Niang"?

\section{Maksud dan Tujuan}

a. Untuk mengetahui pembagian ruang dan fungsi ruang yang ada di rumah Niang

b. Untuk mengetahui proses pembangunan rumah Niang

\section{Batasan masalah}

Menjelaskan fungsi ruang dan proses pembangunan rumah adat Mbaru Niang

\section{METODE PENLITIAN}

Pendekatan yang digunakan dalam penelitian ini adalah pendekatan kualitatif, dikarenakan penelitian ini didasarkan pada permasalahan yang akan dikaji oleh peneliti mengenai prosesi tradisi pembangunan rumah adat tradisional di Desa Wae Rebo yang memerlukan sejumlah data di lapangan yang sifatnya aktual dan kontektual, sehingga peneliti memperoleh gambaran dari permasalahan yang terjadi secara mendalam (berupa teknis, budaya dan lingkungan) dan tidak dituangkan dalam bentuk bilangan atau angka statistik, melainkan tetap dalam bentuk kualitatif. Untuk mendekati maslah-masalah secara naturalistic kepada subjek penelitian baik itu variabel terkait (arsitektur tradisional) maupun variabel bebas (prosesi tradisi pembangunan rumah adat, ketua adat, pemilik/penghuni rumah, masyarakat Wae Rebo), maka peneliti harus mengenali, mengetahui, dan memahami maslaha-masalah tersebut secara teknis, budaya dan lingkungan.

Proses induktif digunakan pada waktu melakukan penelitian makro "arsitektur masyarakat tradisional" dalam menjelajah keberadaan arsitektur tradisional di Desa Wae Rebo. Setelah memperoleh gambaran umum terhadap beberapa rumah adat di masyarakat Wae Rebo baik secara bentuk, karakteristik maupun fungsi ruang, maka dikaji lebih mendalam lagi untuk mengetahui adanya suatu kekuatan "budaya" pada rumah adat tersebut.

Proses induktif dilaksanakan pada penelitian mikro "tradisi dalam arsitektur" dimasyarakat Desa Wae Rebo, dengan focus penelitian pada fenomena upacara tradisi, fenomena perabot dan perlengkapan ritual, fenomenahierarki dan fungsi ruang, fenomena tata letak bangunan dan fenomena bahan bangunan lokal.Fenomena-fenomena tersebut terkait erat dengan proses pembangunan rumah adat masyarakat suku Manggarai sehingga terbentuk konsep teknis, budaya dan lingkungan terhadap arsitektur tradisional.

\section{HASIL DAN PEMBAHASAAN}

\section{A. Fungsi Ruang Rumah Niang}

Mbaru Niang berbentuk kerucut dengan atap yang menghampir menyentuh tanah. Atap yang digunakan rumah adat Mbaru Niang ini menggunakan daun lontar. Mbaru Niang adalah rumah dengan struktur cukup tinggi, berbentuk kerucut yang keseluruhannya ditutup ijuk. Mbaru Niang memiliki 5 tingkat dan terbuat dari kayu worok dan bamboo serta dibangun tanpa menggunakan material buatan. Tali rotan yang 
kuat mengikat konstruksi bangunan. Setiap Mbaru Niang dihuni enam sampai delapan kepala keluarga.

Setiap lantai Mbaru Niang memiliki ruangan dengan fungsi yang berbeda-beda, yaitu :

* Tingkat pertama disebut lutur digunakan sebagai tempat tinggal dan berkumpul dengan keluarga

* Tingkat kedua berupa loteng atau disebut lobo berfungsi untuk menyimpan bahan makanan dan barang-barang sehari-hari

* Tingkat ketiga disebut lentar untuk menyimpan benih-benih tanaman pangan, seperti benih jagung, padi dan kacang-kacangan

* Tingkat keempat disebut lempa rae disediakan untuk stok pangan apabila terjadi kekeringan

* Tingkat kelima hekang kode untuk tempat sesajian persembahan kepada leluhur

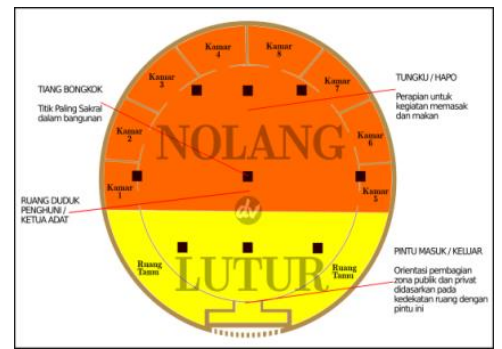

Gambar 1: Denah ruang Mbaru Niang Sumber : google

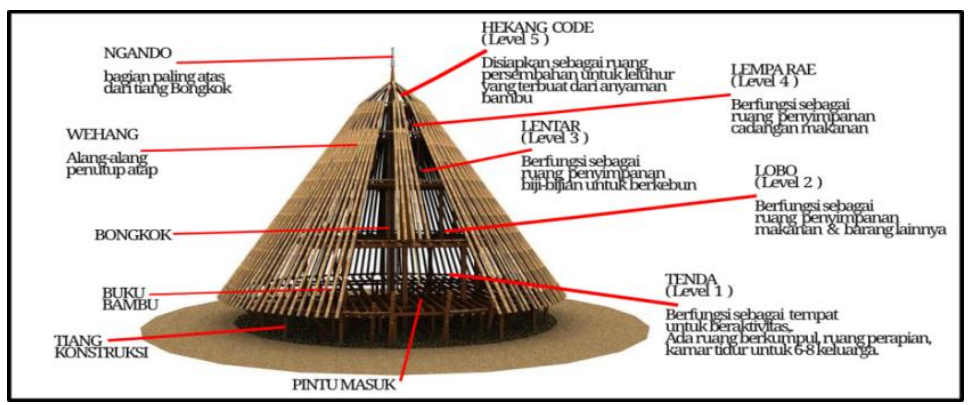

Gambar 2 : Tingkatan Mbaru Niang Sumber : google

\section{B.Prose Pembangunan Mbaru Niang}

\section{Tahap Perencanaan}

Untuk membangun sebuah Mbaru Niang, masyarakat Wae Rebo mempersiapkan hingga satu tahun, karena kesluruhan bahan bangunan diambil secara gotong royong dari hutan yang mengelilingi kampung Wae Rebo yang pimpin oleh ketua adat "Tu'a Golo" dan "Tu'a Teno". Seperti kayu utama yang menjulang ditengah setinggi 15 meter, diambil dari satu pohon utuh dan sebelum dipakai kayu tersebut telah dipersiapkan secara tradisional agar menjadi kayu yang baik dan kuat dan dipilih kayu yang cukup berumur. Selain kayu, masyarakat juga mengumpulkan bermeter-meter rotan untuk mengikat ijuk dan alang-alang untuk atap dan bambu. Seluruh bahan ini dipersiapkan dan dikumpulkan sedikit-sedikit sesuai yang disediakn alam yang dapat diambil secara ritual khusus oleh masyarakat.

\section{Tahap Pembangunan}

a. Pondasi 
Pondasi dari Mbaru Niang terdiri dari beberapa bilang batang kayu yang ditanam ke tanah sedalam 2 meter, terdapat permasalahan pondasi pada bangunan lama, yaitu kayu yang membusuk karena lembab atau rapuh sehingga tak kuat menahan keseluruhan bangunan rumah. Seiring dengan kedatangan tamu dan beberapa masukan dari para ahli, pondasi Mbaru Niang sekarang dibungkus dengan plastic dan iujuk untuk melindungi kayu bersentuhan langsung dengan tanah Wae Rebo yang lembab.

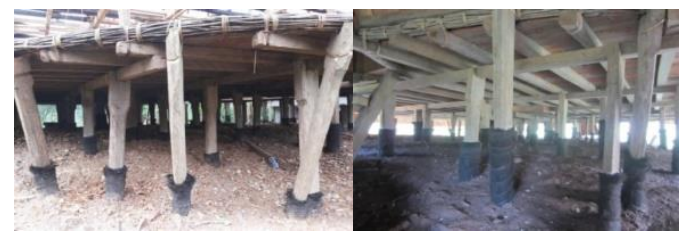

Gambar 3 Pondasi Mbaru Niang

b. Lantai Pertama

Lantai pertama berdiameter 11 meter dan merupakan lantai utama, di mana disinilah kehidupan sosial masyarakat berlangsung. Lantai pertama dibuat segera setelah pondasi selesai dilaksanakan, berlandaskan balok-balok danhamparan papan kayu dan dikelilingiglondongan ikatan rotan besar sebagai dudukan utama atap. Di atas lantai pertama inilah didirikan tiang utama hingga kepucuk Mbaru Niang atau yang sering disebut "Ngando" yang dilengkapi dengan tangga banmbu untuk menaiki setiap tingkat Mbaru Niang.

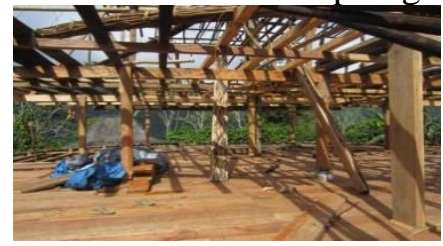

Gambar 4 Lantai satu Mbaru Niang

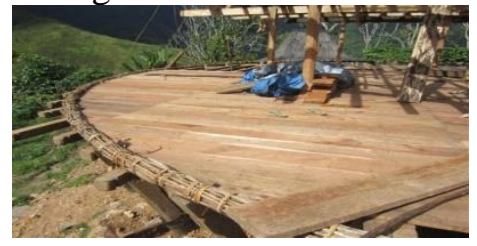

Gambar 5 Lilitan rotan

c. Tiang Utama / Siri Bongkok

Tiang utama / Siri bongkok sebagai penyanggah di mana tiang-tiang yang lain bertumpu dan menjadi symbol bagi masyarakat Manggarai, yaitu symbol persatuan dan kesatuan dan sebagai tempat penyelsaian masalah.

Tiang utama ini berdiri di atas lantai pertama, untuk menyangga tiang utama ini ditahan dengan tali rotan yang diikatkan pada tiga hingga 4 pasak.Tiang utama ini akan menjadi penyangga dari keseluruhan aktivitas pembangunan Mbaru Niang, sehingga sangat diyakinkan ikatan pada pasaknya benar-benar kuat.

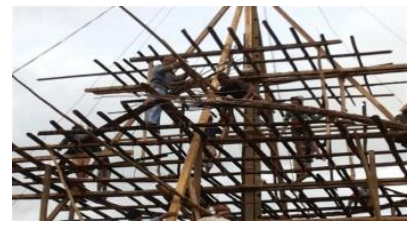

Gambar 6 : Proses Pemasanagan

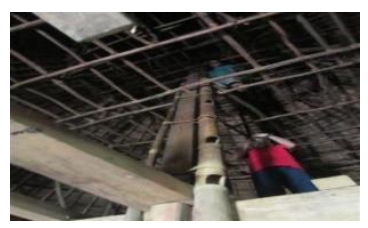

Gambar7 : Tangga Bambu Tiang Utama

d. Penyangga Dinding dan Dinding (atap)

Penyangga dinding yang sekaligus berfungsi sebagai atap ini adalah kumpulan rotan dalam satu ikatan, ukurannya sangat besar dan panjangnya disesuaikan 
dengan keliling lingkaran, jadi yang paling panjang adalah pada lantai satu dan semakin ke atas semakin pendek. Kumpulan rotan inilah yang membentuk bulatan pada Mbaru Niang.

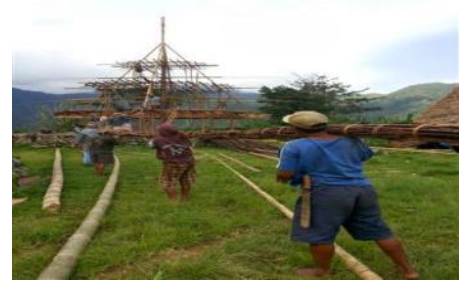

Gambar 8: Pemasangan ikatan rotan

e. Pekerjaan Lanjutan

Setelah lantai pertama dan tiang utama berdiri, pembangunan tiap-tiap lantai akan meneyesuaikan dibangun secara simultan dari lantai bawah terus hingga ke atas. Setelah kesluruhan struktur utama selesai hingga bamboo-bambu pengikat atap siap, barulah pemasangan ijuk dan alang-alang dillaukan untuk menutupi keseluruhan bangunan.

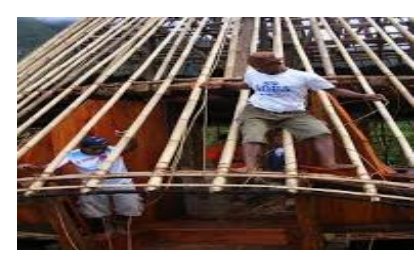

Gambar 9 Proses Pemasanagan

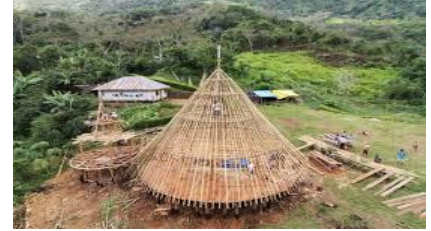

Gambar 10. Rangka Badan struktur atap

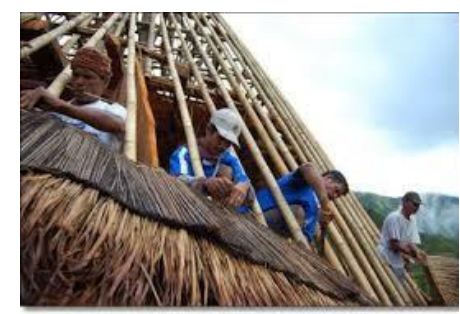

Gambar 11 : Proses pengatapan Mbaru Niang

\section{Tahap Hunian}

Menurut bahasa daerah setempat, we'e mbaru berarti kembali ke rumah. Upacara ini sebagai simbolis penempatan rumah baru oleh penghuni rumah rumah yang sebelumnya menginap di rumah gendang. Makna dari upacar ini adalah untuk mengumpulkan roh para leluhur untuk kembali ke rumah dan sebagai bentuk ungkapan terima kasih kepada Tuhan dan para leluhur Wae Rebo atas perlindungan dan berkah yang diberikan selama proses pembangunan berlangsung. Upacara ini dipimpin oleh ketua adat dan dihadiri oleh semua anggota keluarga penghuni rumah itu serta sebagian masyarakat.

\section{KESIMPULAN}


Rumah "Mbaru Niang" dibangun memiliki makna simbolis yang sangat kuat, di mana konstruksi rumah dibangun dalam lima tingkat. Sedangkan secara fungsional, Mbaru Niang memiliki fungsi yang menjelaskan bagaimana kehidupan itu harus dibangun dan sosialitas mereka terhadap keluarga, masyarakat dan lingkungan mereka. Fungsi ruangruang dalam Mbaru Niang juga mewakili konsep kosmologis. Orang Manggarai memandang rumah tidak hanya sekedar tempat tinggal, tetapi juga sebagai ruang pusat siklus kehidupan dan masyarakat Manggarai yang menghuni di Desa Wae Rebo "Mbaru Niang" merupakan wujud keselarasan manusia dengan alam serta merupakan cerminan fisik dari kehidupan sosial warga Desa Wae Rebo. Karena itu membangun rumah adat didasarkan tradisi dan kepercayaan yang diwarisi secara turun temurun.

\section{DAFTAR PUSTAKA}

Ayatrohaedi, 1986, Kepribadian Budaya Bangsa (local Genius), Pustaka Jaya, Jakarta.

Cassirer, Ernst, Manusia dan Kebudayaan: Sebuah Esei Tentang Manusia, Terj. Alois A. Nugroho (Jakarta: PT Gramedia, 1987).

http://bandanaku.wordpress.com/

https://id.wikipedia.org/w/index.php?title=Mbaru_Niang\&veaction=edit\&section=3

Janggur, Petrus. 2008. Butir-butir Adat Manggarai Buku 1. Ruteng: Artha Gracia

Keling, G. (2017). KEARIFAN BUDAYA MASYARAKAT KAMPUNG TRADISIONAL WAE REBO, MANGGARAI, NUSA TENGGARA TIMUR. Jurnal Penelitian Sejarah dan Nilai Tradisional,23(1),51-62

M Louis (2015). JURNAL INTRA.Vol.3,No. 2, (2015) 580-585

Moleong, Lexy J.MA. Metodologi Penelitian Kualitatif. Bandung:PT.Remaja Rosdakarya, 2002.

M. Blasius (2015). Makna Dari Budaya Yang Tetap di pertahankan dan Struktur Mbaru Niang

Rapoport, Amos 1969. House Form and Culture. Engelwood Cliffs NJ; Prentince Hall

Sumardjo, Jakob, Estetika Paradoks (Bandung: Sunan Ambu Press, 2006). 